\title{
Os jovens e as relações com o saber: elementos para construção de uma pesquisa
}

\author{
Los jóvenes y las relaciones con el saber: elementos para la construcción \\ de una investigación
}

\section{Young people and their relation with knowledge: Elements for construction of an investigation}

\author{
Lucas da Silva Martinez ${ }^{1}$ \\ Dra. Sueli Salva ${ }^{2}$
}

\begin{abstract}
Resumo
Este trabalho busca aprofundar alguns aspectos teóricos de uma pesquisa de mestrado intitulada Os jovens no ensino fundamental e a relação com o saber: um estudo de caso no município de Santa Maria/RS. A pesquisa tem por objetivo refletir sobre o processo de escolarização de jovens com mais de 15 anos de idade que ainda se encontram no Ensino Fundamental visando compreender como os jovens se relacionam com o saber. A distorção idade-série, a produção das situações de fracasso escolar, os índices de avaliação nacional, todos estes corroboram para a evidência deste tema. Compreender quem são os jovens, quais as relações que eles estabelecem entre o saber escolar e em até que ponto a escola privilegia a construção dessa relação, quais as culturas que permeiam a escola e de que forma podemos nos aproximar deles para superar as dificuldades no trajeto escolar e conduzir o processo formativo ultrapassando a distorção idade-série torna-se o eixo central de nossa reflexão.
\end{abstract}

Palavras-Chave: Distorção idade-série, Escolarização, Jovens, Relação com o saber, Situações de fracasso escolar.

\section{Resumen}

En la frontera, la interculturalidad es la base de las relaciones de estar con el otro, que vive en otro país, para Este trabajo pretende profundizar algunos aspectos teóricos de un proyecto de curso master titulado La juventud en la escuela primaria y la relación con el saber: un estudio de caso en la ciudad de Santa Maria/RS. La investigación tiene como objetivo reflexionar sobre el proceso de escolarización de los jóvenes con más de 15 años de edad que todavía están en la escuela primaria con el objetivo de entender cómo los jóvenes se relacionan con el saber. Las distorsión edad-grado, la producción del fracaso escolar, los índices nacionales de evaluación, todos ellos corroboran en la evidencia de este tema. Comprender que son jóvenes, que relaciones establecen entre el saber escolar y el grado en que la escuela da prioridad a la construcción de esta relación, que invaden los cultivos de la escuela y la forma en que pueden acercarse a ellos para superar las dificultades en el camino la escuela y llevar a cabo el proceso de entrenamiento para superar la edad-grado se convierte en el eje central de nuestro pensamiento.

Palabras clave: Distorsión edad-grado, Escolarización, Joven, Las situaciones de fracaso escolar, Relación con el saber.

\footnotetext{
1 Mestrando em Educação; Universidade Federal de Santa Maria - UFSM, Rio Grande do Sul, Brasil; lukasspedagogia@gmail.com

2 Doutora em Educação; Universidade Federal de Santa Maria - UFSM, Rio Grande do Sul, Brasil; susalvaa@gmail.com
} 


\begin{abstract}
In the frontier intercultural is the relationship basement to be with others, to be in other countries and to be in This research wants deepen in some theorists aspects by on project of master research named Os jovens no ensino fundamental e a relação com o saber: um estudo de caso no município de Santa Maria/RS. This research have the objective to reflect about the schooling process the young with more of 15 years, who was in the primary school, seeking out how the young people are related with the knowledge. The distortion age-serie, the production of the school failure, the national indexes of evaluation, all them corroborate for the evidency on this demand. Understand who are they youngs people, how relations they establish between the scholar knowledge and the series and also the priority who the school give to the building of this relations, that invade the crops pf the school and how they can approach of then to overcome the difficulties on the way of the school and take the training process to overcome the series-age who turn over in the central point of our think.
\end{abstract}

Keywords: Distortion age-, Schooling, Young, situation of Scholar Failure, Relationship with knowledge.

\title{
1. Introdução
}

Este trabalho busca aprofundar alguns aspectos teóricos de uma pesquisa de mestrado intitulada Os jovens no ensino fundamental e a relação com o saber: um estudo de caso no município de Santa Maria/RS .

A pesquisa de mestrado tem por objetivo refletir sobre o processo de escolarização de jovens com mais de 15 anos de idade que ainda se encontram no Ensino Fundamental visando compreender como os jovens se relacionam com o saber. Para isto, baseia-se na concepção de "relação com o saber" a partir da perspectiva teórica de Charlot (2000, 2001, 2002), que procura “(...) compreender qual é o tipo de relação com o mundo e com o saber que a criança deve construir, com a ajuda da escola, para ter acesso ao pleno uso das potencialidades escondidas na mente humana" (CHARLOT, 2002, p.65).

A escolarização de jovens com mais de quinze anos de idade no Ensino Fundamental está permeada de exclusões, reprovações entre outros fatores que resultam em índices de distorção idade-série. Hoje, “(...) a realidade educacional brasileira atual traz evidências de que ter a idade entre 15 e 17 anos e estar fora da escola, ou em defasagem idade-série, é a situação de quase metade do universo de adolescentes brasileiros dessa faixa etária" (ESTRÁZULAS, et al., 2013, p. 1). Dados ${ }^{4}$ revelam que a o percentual de distorção idadesérie no município giram em torno de $30 \%$, ou seja, a cada 100 alunos, 30 estão em turmas com idades superiores ao previsto.

A justificativa para a construção desta pesquisa é proveniente da experiência enquanto bolsista de graduação na Universidade Federal do Pampa e conselheiro municipal de

\footnotetext{
${ }^{3}$ Pesquisa realizada no Programa de Pós-Graduação em Educação pela Universidade Federal de Santa Maria, orientado pela professora doutora Sueli Salva.

${ }^{4}$ Dados obtidos através do site < $\underline{\text { http://www.qedu.org.br/>. }}$
} 

e-ISSN 2016/Atual: 2525-7870 | e-ISSN 2015/2016: 2447-018X

Educação, no município de Jaguarão/RS. Desde o início da graduação em 2012 ingressei no PIBID $^{5}$ (Programa Institucional de Bolsas de Iniciação à Docência), onde atuei na Educação Especial e, também, me aproximei da Educação de Jovens e Adultos. Estes três anos e meio como bolsista me possibilitam a estar em contato com a escola pública e com as crianças, jovens e adultos que ocupam este espaço.

A distorção idade-série, a produção das situações de fracasso escolar, os índices de avaliação nacional, todos estes corroboram para a evidência deste tema. Na perspectiva do Charlot (2000), não existe "fracasso escolar", mas alunos que se encontram em situação de fracasso. Analisar essa situação de fracasso, portanto, requer compreender que o mesmo não é um objeto simples de compreender e, sim, possui uma multiplicidade de fatores. Assim, a forma de compreendê-la, de acordo com o autor, é analisando a relação que estabelecemos com o saber, enquanto forma de relação consigo, com os outros e com o mundo.

Após essa primeira contextualização, apresentamos algumas reflexões teóricas que subsidiam o estudo da juventude dentro desta pesquisa, buscando aproximar o conhecimento que se tem hoje sobre o processo de escolarização dos jovens no ensino fundamental.

\section{Da relação com o saber: pensando o processo educativo e o público jovem}

A distorção idade-série e a situação de fracasso escolar atualmente vêm se situando na política educacional, mesmo de forma tímida. A meta número 3 do Plano Nacional de Educação, aprovado em 2014 sinaliza a necessidade de elevar a escolaridade de jovens entre 15 e 17 anos para o ingresso no Ensino Médio. A estratégia $n^{\circ} 10$ desta meta aponta que é preciso

(...) fomentar programas de educação e de cultura para a população urbana e do campo de jovens, na faixa etária de 15 (quinze) a 17 (dezessete) anos, e de adultos, com qualificação social e profissional para aqueles que estejam fora da escola e com defasagem no fluxo escolar (BRASIL, 2014).

Em 2011, o Fundo das Nações Unidas para a Infância - UNICEF aponta que desde os primeiros anos de escolarização no ensino fundamental começa a distorção idade-série e a reprovação e, “(...) vai se tornando mais grave nas séries mais avançadas, até limitar o acesso

\footnotetext{
5 Subprojeto Pedagogia. De 2012 à 2014 intitulado: Alfabetização e Educação Inclusiva, orientado pelos professores Everton de Oliveira e Patrícia Moura. De 2014 ao presente momento, intitulado: Modalidades de Ensino: Educação Especial e EJA, orientado pelo professor Everton de Oliveira.
} 
ao nível médio de educação. Em 2009, 13\% das crianças e adolescentes de 10 a 14 anos tinham atraso escolar superior a dois anos" (UNICEF, 2011, p.31).

O caderno Brasil (2011) contribui para a discussão sobre a escolarização de jovens de 15 a 17 anos no ensino fundamental ressaltando a importância da adaptação curricular à população e suas características juvenis, à visão destes sujeitos como sujeitos de direitos, em uma sociedade que se quer cada vez mais democrática. Dayrell, Nogueira e Miranda (2011) compreendem a juventude para além das mudanças biológicas, mas como etapa da vida que se consolida através de sua diversidade.

Dessa forma, compreende-se que:

A juventude é uma categoria socialmente construída e ganha contornos próprios em contextos históricos, sociais e culturais distintos, marcada pela diversidade nas condições sociais (origem de classe, por exemplo), culturais (etnias, identidades religiosas, valores, etc), de gênero e, até mesmo geográficas, dentre outros aspectos (DAYRELL; NOGUEIRA; MIRANDA, 2011, p.15).

Dayrell (2003) indica algumas imagens da juventude no cotidiano que nos ajudam a compreender a juventude e sua complexidade, entre elas: o jovem enquanto momento de transição para a fase adulta; a juventude como tempo de liberdade e prazer sem compromisso; a representação da juventude apenas nos espaços de cultura e lazer, resumido a juventude às atividades realiza nos fins de semana e; a juventude como período de crise, entre a autoestima e a personalidade. Ao fim, concordamos com Dayrell (2003, p.42) ao afirma que entende a juventude “(...) como parte de um processo mais amplo de constituição dos sujeitos, mas que tem especificidades que marcam a vida de cada um. A juventude constitui um momento determinado, mas não se reduz a uma passagem; ela assume uma importância em si mesma”. Camacho (2004) ressalta que a juventude por ser construída socialmente e culturalmente faz com que passe por mudanças através de seu contexto. Nesse sentido, é difícil conceber uma juventude e sim juventudes.

A investigação proposta por Tomazetti et al., (2014) com jovens do Ensino Médio traz alguns questionamentos que podem ser replicados:

Quem são os jovens que frequentam o Ensino Médio? Quais seus projetos de vida? Com quais culturas juvenis esses jovens se identificam? O que pensam sobre educação/ensino? Como as escolas de Ensino Médio são consideradas para esses jovens? As culturas juvenis estão presentes na cultura escolar? Como o jovem vivencia sua experiência no Ensino Médio? Como concilia a sua cultura com a cultura escolar? Como negocia espaços de poder e liberdades dentro da escola? (TOMAZETTI, et al., 2014, p. 13, grifo nosso). 
Os autores Tomazetti et al., (2014) apontam que uma das formas de compreender e se aproximar dos jovens e sua cultura é através do ato de ouvi-los, porem não é simples esta aproximação. Entender que ouvir é o início desta aproximação consiste acreditar que os jovens tem algo legítimo a dizer. Assim, “Talvez através dessas vozes possamos construir caminhos para que a escola seja um lugar onde todos se sintam à vontade, onde todos possam expressar seu ponto de vista, onde todos percebam que a escola é um lugar de crescimento (...)” (p. 71). Melucci (1997, apud TOMAZETTI et al., 2014) aponta que através da escuta poderemos reduzir a distância entre o universo dos jovens e o nosso, dos professores professoras, muitas vezes jovens também. No entanto, para reduzir essa distância é preciso ter claro que:

A escola vem sofrendo um processo de inadequação no tratamento aos seus alunos ao não reconhecê-los como jovens. Este quadro acaba desencadeando impactos como: a desinstitucionalização da condição juvenil, a dificuldade dos alunos na construção da sua identificação com a escola e a ruptura da comunicação entre jovens alunos e educadores (CAMACHO, 2004, p.325).

A autora continua afirmando que pelo fato dos professores e professoras não conseguirem delimitar quem são os jovens, eles o consideram sem identidade, impedindo sua devida valorização como jovem em uma escola plural e democrática (CAMACHO, 2004).

Charlot (2000) argumenta que o fracasso escolar não é um objeto claro de pesquisa, como se constitui a partir da década de 1970, até os dias atuais. As diferentes rotulações, dentre as quais a de que a origem social é a causa do fracasso escolar, ou a de que os alunos que fracassam são deficientes socioculturais mascaram o verdadeiro fato: a fragilidade da relação com o saber produzido na escola, que se espera que os alunos aprendam, dessa forma “(...) esse saber pouco apoio recebe do tipo de relação com o mundo (descontextualização, objetivação, argumentação (...)" (CHARLOT, 2000, p.64).

Entender a relação que os alunos estabelecem com o saber pode contribuir para que o professor possa organizar os objetos do conhecimento que tenham maior potencial para que se estabeleçam relações. Assim, poderíamos na cultura escolar propiciar formas de superar as "situações-limite" (FREIRE, 1983), entendidas como situações esmagadoras, nas quais ficamos sem ação. Consideramos "situações-limite" a distorção de idade/série, a reprovação, a exclusão. E, como meta, chegar à um "inédito viável" através de uma proposta educativa que propiciasse a relação com o saber, compreendendo esta como a relação que fazemos com o mundo, com os saberes escolares, os saberes da relação com o professor e o aluno, entre outros saberes imbricados no ser e estar no mundo. 
A relação com o saber é uma relação com o aprender, e o saber é mais do que um "saber-objeto", mas o saber é a própria relação. Neste sentido, "a relação com o saber é relação de um sujeito com o mundo, com ele mesmo e com os outros" (CHARLOT, 2000, p.62).

Estudar essa relação implica reconhecer que a mesma precisa de trabalho intelectual por parte dos alunos que, envolve o desejo de aprender e estarem mobilizados, quando isto se relaciona com sua dimensão pessoal, ou seja, “(...) um saber só tem sentido e valor por referência às relações que supõe e produz com o mundo, consigo, com os outros" (CHARLOT, 2000, p.64).

Matos (2008, p.21) corrobora com esta ideia ao afirmar que a relação com o saber é “(...) é indissociavelmente cognitiva, afetiva e relacional”, implicando também “(...) uma construção pessoal do seu sentido por parte dos alunos ao serviço do sentido da própria existência, que constituirá a base da nova motivação para o trabalho escolar”.

A investigação tenta promover aproximação com os jovens e através disso possibilitar que os jovens produzam "discursos sobre si próprios, sobre os saberes que constroem, dentro e fora da escola e, sobre a sociedade da qual participam" (SALVA, 2008, p.29). Assim, o processo de produção do conhecimento através do pesquisador se dá através da união entre objetividade e subjetividade (FREIRE, 2006), considerando-os não apenas objetos, mas também sujeitos da pesquisa, retornando à ideia de que, os alunos são mais do que agentes, são sujeitos que possuem subjetividade (CHARLOT, 2000).

\section{Considerações provisórias}

Freire (2016) considera que nós professores e professoras precisamos aprender a escutar os estudantes, para assim, poder aprender a falar com eles, estando disponível ao diálogo, ao gesto e as diferenças do outro. Investir no tema da juventude requer disponibilidade para entrar em um campo instável, por vezes distante porém de atualidade e emergência significativa.

O compromisso pela educação se faz através da efetivação de políticas públicas de qualidade que atendam todas as modalidades de ensino e etapas da educação, qualificando a passagem pelos espaços escolares em todas as idades. Dessa forma, apostamos no diálogo e na escuta atenta como forma de aprofundar nosso conhecimento sobre as culturas juvenis, uma vez que “(...) os próprios jovens sinalizam que 'o aluno não é mais o mesmo’, e nós, enquanto educadores, necessitamos saber, afinal, quem é esse aluno" (TOMAZETTI et al., 
2014, p. 97). Compreender quem são os jovens, quais as relações que eles estabelecem entre o saber escolar e em até que ponto a escola privilegia a construção dessa relação, quais as culturas que permeiam a escola e de que forma podemos nos aproximar deles para superar as dificuldades no trajeto escolar e conduzir o processo formativo ultrapassando a distorção idade-série torna-se o eixo central de nossa reflexão.

Finalizando, é possível apontar que a pesquisa pode contribuir dando visibilidade aos jovens estudantes para além da identidade de aluno, compreender aspectos relativos a sua relação com o saber e, quem sabe interferir na construção de políticas públicas no que confere as especificidades da juventude e a importância da relação com o saber que os jovens estabelecem, sendo esta também relação com o saber-objeto, e com os professores e professoras.

\section{Referências}

BRASIL. Ministério da Educação. Secretaria de Educação Básica. Caderno de reflexões: jovens de 15 a 17 anos no Ensino Fundamental. Brasília: Via Comunicação, 2011.

Ministério da Educação. Secretaria de Articulação com os Sistemas de Ensino (MEC/SASE). Planejando a Próxima Década: Conhecendo as 20 Metas do Plano Nacional de Educação. Brasília: MEC, SASE, 2014. Disponível em: $\langle$ http://pne.mec.gov.br/images/pdf/pne_conhecendo_20_metas.pdf $>$. Acesso em: 15 jan. 2015

CAMACHO, Luiza Mitiko Yshiguro. A invisibilidade da juventude na vida escolar. PERSPECTIVA, Florianópolis, v. 22, n. 02, p. 325-343, jul./dez. 2004

CHARLOT, Bernard. Da relação com o saber: Elementos para uma teoria. Porto Alegre: Artmed, 2000

.Os jovens e o saber: Perspectivas mundiais. Porto Alegre: Editora Artmed, 2001

. Relação com a escola e o saber nos bairros populares. Revista Perspectiva, v.20, n. Especial, Jul/Dez 2002

DAYRELL, Juarez. O jovem como sujeito social. Revista Brasileira de Educação. n.24, p.4052, set/dez, 2003

.; NOGUEIRA, Paulo Henrique de Queiroz.; MIRANDA, Shirley de Aparecida.; Uma introdução: juventude ou juventudes? In: BRASIL. Ministério da Educação. Secretaria de Educação Básica. Caderno de reflexões: jovens de 15 a 17 anos no Ensino Fundamental. Brasília: Via Comunicação, 2011.

ESTRÁZULAS, Mônica Batista Pereira et al., Projeto Trajetórias Criativas: Uma proposta metodológica para o atendimento de jovens de 15 a 17 anos no ensino fundamental. In: $31^{\circ}$ SEURS - Seminário de Extensão Universitária da Região Sul, 2013, Florianópolis. Anais 

e-ISSN 2016/Atual: 2525-7870 | e-ISSN 2015/2016: 2447-018X

do $31^{\circ}$ SEURS - Seminário de Extensão Universitária da Região Sul, 2013. Disponível em: <https://repositorio.ufsc.br/handle/123456789/117316>. Acesso em : 4 nov. 2015

FREIRE, Paulo. Pedagogia do Oprimido. 16a ed. Rio de Janeiro: Paz e Terra, 1983.

Criando métodos de pesquisa alternativa: aprendendo a fazê-la melhor através da ação. In: BRANDÃO, C. R (org). Pesquisa participante. São Paulo: Brasiliense, 2006

Pedagogia da autonomia: saberes necessários à prática educativa. $53^{\mathrm{a}}$ ed. Rio de Janeiro: Paz e Terra, 2016

MATOS, Manuel. Jovens, alunos, ensino secundário: um mundo crescente de contradições. Revista Educação, Sociedade \& Culturas. n.27, 2008. Revista do Cento de Investigação e Intervenção Educativa. Porto: Edições Afrontamento, 2008.

MELUCCI, Alberto. Juventude, Tempo e Movimentos Sociais. Revista Brasileira de Educação. n.5 e n.6, p.5-14, mai/ago. - set/dez, 1997

SALVA, Sueli. Narrativas da Vivência Juvenil Feminina: histórias e poéticas produzidas por jovens de periferia urbana de Porto Alegre. Porto Alegre, 2009, 329F. Tese (Doutorado) Programa de Pós-Graduação em Educação. Faculdade de Educação. Universidade Federal do Rio Grande do Sul, Porto Alegre, 2008.

TOMAZETTI, Elizete et al. (Orgs.). Os sentidos do Ensino Médio: Olhares juvenis sobre a escola contemporânea. 2. ed. rev. ampl. São Leopoldo: Oikos, 2014.

UNICEF. Situação da Adolescência no Brasil. O direito de ser adolescente: Oportunidade para reduzir vulnerabilidade e superar desigualdades. Brasília, DF: UNICEF, 2011. 